\title{
MIND-BRAIN AND BODY IN THE SELF: Psychoanalytic Perspectives
}

\author{
W. W. Meissner, S. J.
}

In attempting to think about the nature of the self in psychoanalysis, exploration of the issues involved leads inevitably to consideration of the mind-body relation and its implications for understanding the self. In previous reflections, I have discussed the varieties of mind-body relation proposed by various theorists (Meissner, 2003b) as well as the vagaries of thinking about the mind-body relation found in Freud (Meissner, 2003c) and among subsequent analysts who have reflected on the matter (Meissner, 2003d). Subsequent exploration of neuroscientific findings relevant to the mind-brain problem (Meissner, 2006a, $2006 \mathrm{~b}$ ), of conclusions from the study of brain dysfunction in forms of psychopathology and dreaming (Meissner, 2006c) and of aspects of psychosomatic functioning (Meissner, 2006d) led to the conclusion that traditional dualistic and monistic resolutions of the mind-body problem were insufficient.

I (Meissner, 2006c) stated my tentative conclusion in the following terms:

I have argued here for a more complex resolution, one that recognizes the activity of the mind-conscious and unconscious, voluntary and involuntary, explicit and implicit-as produced by brain processes, but as retaining their separate and distinctive character as studied by mental and psychological disciplines. In this sense, the separate methodologies-one neuroscientific and objective studying physical brain mechanisms and processes by external observational and technologically manipulative techniques, the other introspective and subjective studying mental processes from the inside, seeking an understanding of the meanings and motivations involved in mental activities-can serve as separate and distinct and complementary approaches to the study of the 
same underlying unified mind-brain organization. While the methodological chasm that separates them does not allow any extent of neuroscientific sophistication to shed any light on the subjective meaning and motivation of mental processes, nor any development in psychological sophistication to tell us anything about brain organization and functioning, our understanding of the complex reality they both seek to grasp from their respective vantage points cannot be encompassed without the contributions of both approaches, hopefully leading to a more integrated and comprehensive knowledge of the complexities of the integrated and unified reality of the mind-body entity itself. (pp. 194-195)

Others have come to similar conclusions, but few have undertaken to relate these conclusions to psychoanalytic concerns. The implications of this complex resolution of the mind-body problem also impinge directly on questions concerning the connections between psychoanalytic understandings and emerging neuroscientific discoveries. I would submit that progress in these matters would be greatly facilitated by a clear understanding of the issues involved and specifically by a grasp of the inherent integrity and unity of the mind-body relation, specifically in the form of the mind-brain continuum.

But my purpose in the present discussion is not to argue to the integrity and unity of the mind-body relation, as proposed by others and in my own previous considerations, but to integrate these conclusions with the concept of the self, conceived as synonymous with the human person as embodied (i.e., as constituted by the totality of the body self). Thus the scope of my discussion here is consequently quite limited, namely, to bring together these conclusions regarding mind-body unity and integrate them with the concept of self-as-person (Meissner, 2001). The core questions confronting us in this welter of fact and opinion were posed nearly a score of years ago by Rorty (1988): "What accounts for the unity and identity of any individual mind, and how do the unity and identity of mind differ from the unity and identity of an individual person, composed of mind and body?" (p. 3). My purpose in the present essay is to suggest a way of thinking about these problems that seem to me to be more thoroughly consistent with analytic interests and concerns.

I propose to approach this problem by, first, reviewing 
some conclusions regarding the mind-brain relation that might circumvent the dual pitfalls of dualism versus reductionistic monism $^{1}$; second, by addressing the concept of mental acts and forms of brain activation as conceived by current neuroscientific understanding; third, by surveying some of the ways in which integration of mind-and-body is conceived in current neurobehavioral constructions; and, finally, by discussing the implications of these conclusions for formulating a concept of the mind-brain-body in relation to the concept of the self-as-person.

\section{MIND, BRAIN AND BODY IN THE SELF}

The mind versus body distinction is deeply embedded in how we think about ourselves, in commonsense if not philosophical terms. As Rorty (1979) commented: "We seem to have no doubt that pains, moods, images, and sentences which 'flash before the mind,' dreams, hallucinations, beliefs, attitudes, desires, and intentions all count as 'mental' whereas the contractions of the stomach which cause the pain, the neural processes which accompany it, and everything else which can be given a firm location within the body count as nonmental" (p. 17). The distinction has a certain face validity, but as long as we remain within that compass, we are entrenched in dualism. The resolution of the mind-body relation we seek requires integration of mind and body that allows us to transcend dualistic fixations and obtain more meaningful reconciliation between current neuroscientific and psychoanalytic-psychological understanding of human behavior.

One important aspect of this problematic is the relation between the tripartite structural theory and the brain processes and systems subserving these functions. After all, id, ego, and superego are groupings of mental functions expressing the patterns of organization and functioning of the agency of the selfsystem (Meissner, 2000a, 2000b, 2000c); as such, they reflect or express the activity of brain processes and systems effecting these patterns of functional activity. The basic question, then, is How are these patterns of mental activity produced by brain systems? $?^{2}$ The understanding we are looking for must be respectful of both the reality and functionality of the brain and at the 
same time equally respectful of the reality and functionality of the mind without slipping into the conceptual tangles of dualism or monism of whatever kind. We also require a theory of mind and body that encompasses their integration into a unified and functional entity. The solution we adopt, therefore, we hope would escape the disadvantages of both dualism and monism. The first issue, then, we need to address is the relation of the brain to both mental and physical forms of behavior. ${ }^{3}$

\section{Brain and Action}

My argument here centers on the concept of mental activity as equivalently actions of the brain. In this view brain activity is involved in and is the source of all mental actions-thinking, feeling, imagining, fantasying, dreaming, and so on. This orientation to the mind-brain relation has been endorsed by a variety of theorists. Erwin (2002) recently came to a similar conclusion: After reviewing Freud's views on the mind-body relation and rejecting the usual alternatives, he concluded: "One could consistently combine Freudian theory with an interactive form of 'property dualism,' the theory that there is no substance or entity called the mind, but that there are mental states and events that are not identical with neurological states, although they may be causally dependent on them" (p. 345). Or in Andreasen's (2001) phrasing: "There are two different words that refer to the same thing/activity, and neither exists without the other in living human beings. What we call the mind is the product of activity occurring in the brain at the molecular, cellular and anatomical levels" (p. 27). Likewise, Damasio (1994) expressed this integrative view in the following propositions:

(1) The human brain and the rest of the body constitute an indissoluble organism, integrated by means of mutually interactive biochemical and neural regulatory circuits (including endocrine, immune, and autonomic neural components); (2) The organism interacts with the environment as an ensemble: the interaction is neither of the body alone nor of the brain alone; (3) The physiological operations that we call mind are derived from the structural and functional ensemble rather than from the brain alone: mental phenomena can be fully understood only in the context of an organism's interacting in an environment. (pp. xvi-xvii) ${ }^{4}$ 
Such a view repudiates Cartesian and related forms of dualism (the mind is not a substance or separate process) and any form of material monism (neural and mental states are not simply identical), yet leaving open the possibility of some form of relation and dependence.

The first point is that mental events are brain actions. To begin with, in considering the role of the brain in actions of any kind, we generally make a clear distinction between actions that are mental and those that are physical. If I think about the concept of an isoceles triangle, I regard both the thinking and the concept of triangle as mental. The triangle concept is abstract and does not exist in reality-real triangles can only approximate an isoceles form but never fully realize it: There is always some minor deviation from geometric perfection. If I try to construct a triangular form out of pieces of wood, those actions are physical, not mental: They are guided by the idea or image of the triangle but are themselves of a different order. There is no question that the triangle concept is mental, but what about the thinking? If the thinking is mental, as the dualist would contend, should it not come from a mental source? But this would presume what needs to be proven, that there is a mental source independent of the brain. But what if we were to regard the brain as source of the thinking? What if thinking is one of the things the brain does? $?^{5}$ As a result of neuroimaging techniques and cellular microrecording (Meissner, 2006a, 2000b), we can watch the brain go into action and even trace patterns of activation in brain cells and their complex connections in performing such mental actions. As Goleman (1995) commented: "Most dramatic are the glimpses of the brain at work, made possible by innovative methods such as new brain-imaging technologies. They have made visible for the first time in human history what has always been a source of deep mystery: exactly how this intricate mass of cells operates while we think and feel, imagine and dream" (p. xi). If we did not presume a fundamental dualism, would we not have reason to think that the brain in these complex integrations of its functional capacity was actually the source of the actions we experience?

In this case thinking the concept of triangle would be a brain action and to that extent also somatic, but the action con- 
sidered with regard to the concept would still be mental. In this context, rather than the substantive term "mind," which tends to sustain more-or-less reified connotations reinforcing a dualistic construction, we might better think in terms of "mental activities," that is, activities expressing one form or forms of brain action, thereby constituting one form of "psychophysical activities" (Rorty, 1988, p. 5). Along similar lines, Stoller (1979) had cautioned that as long as we used words like "mind" as substantive nouns, we are at risk of falling into the Cartesian dualistic trap. But, seeking to avoid the Cartesian solution, he took a subjectivist and epiphenomenal turn, also arguing that when we use terms like "body" or "mind" we are referring to experiences, not things. Thus the term "I" became for him nothing more than a symbolic construct of the brain without any existence apart from or beyond that organ. ${ }^{6}$ What, he objected, was there to prevent self-awareness from evolving along with the increasing complexity of brain structure? But, in thus avoiding the dualist trap, he fell into a reductionist resolution-namely, that if "mind" was not a substantive, what was it? I am seeking to advance an answer in terms that do not simply reduce mind to the status of a function of brain activity, even though it is constituted by and dependent on brain actions.

In what sense, then, can we argue that the brain can perform mental actions? This carries us to the questions of agency and causality. When I play chess, I do a lot of thinking-analyzing the board, calculating positions of pieces (my own and my opponent's), planning sequences of possible moves, thinking about game strategy, and the like. All of this is mental. At some point, I make a decision and move a piece. Moving the piece is physical. My thinking and decision making lead to making the move: Is this no more than a Humean sequence (i.e., moving simply follows thinking) or is there some real causal connection? How can mental processes result in physical moves? My mental preparation, concentration, imagining, planning sequences of moves, and so on are all mental and lead to physically moving the piece. What do we take to be real in all this? Obviously all of it, but if I make a bad move in chess the corrective analysis focuses on the mental process-what I did not think about or did not take into consideration in my decision to move the piece. 
How I move the piece physically is incidental. Mental processes result in physical moves and both are regarded as integral to the game and its outcome.

Daily life experience is crammed with such experiences in which we see mental and physical blended in sequences in which we do not hesitate to say that one influences and even causes the other. If we can watch the brain in action, and even record the modifications of activity of cells and cell assemblies in the performance of complex tasks-as we do in using advanced imaging and cellular recording techniques-what prevents us from concluding that these actions are being performed by the brain itself and not some other putative and theoretical reality? The question of causality is central here. The operations of the brain are immersed in physical causality-every synapse involves causal influences from the presynaptic neuron producing effects in the postsynaptic neuron. When a sequence of such effects in the neural net, by combinations of convergence, divergence, and combined and parallel processing, result in a mental action, for example, a thought, image, or feeling, does the brain action cause the mental effect? ${ }^{7}$

If I say Yes, do I not imply that cause and effect are distinct and thus bring upon myself the basic dualistic conundrum of how the physical brain can cause a mental effect? I would rather say that the mental actions are brain actions, rather than that a set of physical actions causes mental actions. The action of the mind is the action of the brain. A different sequence is involved when I decide to move my arm. The decision process is a form of brain action which is also mental; the neural potentials generated in that process are directed to the appropriate area of motor cortex, hence to motor cells whose axons terminate at neuromotor junctions on the corresponding muscle groups causing them to contract, thus producing the movement. I submit that there is a causal sequence involved that is essentially physical from beginning to end of the process. In this sense there is no question of mental action producing a physical effect, since the decision process itself is synonymously a form of brain actionactivation of the brain cells involved in the decision process activate other neural cell assemblies causing motor behavior.

But taking such a position may confront us with some seri- 
ous difficulties. First, does this view amount to another brand of neural identity theory that in the long run reduces mind to brain? An important corollary is that attribution of mental events to brain action is not in this sense reductionistic, although it may be regarded as reductive. I would think that, if the brain is the source of mental activity, that fact does not diminish the reality and value or the inherent quality and intelligibility of the mental activity in its own right.

To be clear about my use of the distinction between the reductionistic and the reductive, if we regard the solution as reductionistic, its force would be to reduce mind to brain and replace explanations of mental activity by alternate explanations based on the physical brain: for example, reducing ego functions to constellations of brain processes-similar to the manner in which chemical reactions are explained by appeal to physical mechanisms and processes. In other words, the psychological meanings and explanations of mental actions would be replaced by explanations based on brain processes. But if the solution goes no further than to attribute mental events to the activity of brain processes while recognizing that our understanding of mental events cannot be replaced by explanations in terms of brain mechanisms and processes, the solution would be reductive rather than reductionistic.

In these terms, if I say that Shakespeare's sonnets were products of his brain activity, that does not diminish the beauty and value of the sonnets nor does it offer any explanation of these qualities nor of their content. Appreciation of the sonnets' meaning and literary value cannot be accomplished by study of brain processes, but only by literary criticism. Similarly, the understanding, analysis, and conceptual manipulation of the concept of triangle are part of the mathematical reasoning of geometry. I can understand nothing about geometry by study of the neuronal organizations that give rise to the thoughts about geometry, beyond the conclusion that these brain parts are involved in the process. Geometry is a separate area of mathematics that must be studied on its own terms quite separately from brain processes. Even mental processes dealing with ethical decision and principles retain their independent intelligibility and validity (Meissner, 2003a). Ethical processing, judgment, and de- 
cision making are also products of brain activity, but this does not diminish, devalue, or abrogate ethical deliberation and decision making on its own terms. Principles of morality, ethical judgment, will, and freedom of the will are not compromised in any sense by attributing the origins to patterns of brain activation.

Similarly, students of chess do not explore the brain processes involved in understanding chess in order to better understand and play the game. They study classic chess games, try to better understand game strategy and sequences, and gain more skill and experience by playing lots of games. In these instances and more, if we make distinctions about the realistic implications and results of various forms of behavior and do so independently of the analysis of brain mechanisms involved in their performance, we do not thereby do away with or deny the causal relevance of the mental processes and the brain events involved in them. We accept the behavioral events and brain processes as real and valid, each on their own terms, and understand them as causally related.

A related consideration is the issue of agency. I have explored this issue previously in relation to the concept of the selfas-agent (Meissner, 1993). My conclusion was that there is only one agent involved in the actions of the self, namely, the self as synonymous with the human person. In this light, the statement that thinking is an action of the brain requires parsing. The brain enacts a series of processes effecting a mental action, for example, a thought. Does the brain then think? Here the semantics can be misleading. There is a sense in which the brain does the thinking, as I have been arguing, but the thinking is not thinking of the brain but of the person. In this sense, it is not my brain that thinks, but I think and the process of my thinking is mediated, effected, caused by my brain. I think using my brain. If I postulate the brain as agent of thinking separate from myself, I invite the illusion of the ghost in the machine (Ryle, 1949). But there is no ghost, or if there is a ghost it is myself as acting.

In other words, my acting self is a body self (Meissner, 1997, 1998a), one component of which is the brain. The situation is analogous semantically to psychoanalytic attributions of activity 
to ego or superego as agencies in the mental apparatus-a common enough practice. But ego and superego are no more than constructs allowing us to categorize groups of mental functions of the self (Meissner, 2000a, 2000b, 2000c). When I say the ego decides, for example, it is not the ego that acts as the agent of deciding but the self performing certain ego-functions, that is, I decide, not my ego-specifically, I decide in virtue of my ego capacities and functions. Likewise, when I speak of the superego criticizing, the action is that of the self performing a superego function. The self then acts in virtue of functions that can be grouped and categorized in such fashion. If I take the statements literally, I entertain the fallacy of misplaced concreteness; the statement in fact asserts a figure of speech, synecdoche substituting the part for the whole, the ego or superego for the self. Similarly, when I say the brain acts I am really saying that I act in virtue of certain brain functions. Attributing thinking to the brain is a shorthand expression for action of the self utilizing brain functions; if intended literally that too would amount to a form of misplaced concreteness and synecdoche.

So far as I can see, this fact of life contradicts any reductive monistic analysis, like that advanced by Crick (1994): "'You,' your joys and your sorrows, your memories and your ambitions, your sense of personal identity and free will, are in fact no more than the behavior of a vast assembly of nerve cells and their associated molecules" (p. 3). We might be able to accept this as a statement proposing that mental actions are caused by brain activities, were it not for the unfortunate "no more than." Can we really accept or settle for the view that all of the attributes he mentions, equivalently attributes of the self-as-person, and thus aspects of the functioning of the self that are in the center of psychoanalytic interest, are no more than patterns of activation of the neural net? On the question of what to do with the "no more than," the whole issue of the mind-brain relation pivots. In other words, if there is a form of identity at work here it must be one that insists not only on a methodological and linguistic differentiation between brain and mind, but on a real and functional distinction between them. Stewart (1997), the philosopher of mind, hinted at something similar; her position was paraphrased by Wilson (2005) to the effect "that the mental is both 
caused by and is a feature of the brain but cannot be reduced to descriptions of brain functioning because then the subjective, qualitative experience of the mental would be lost. What is crucial, as Stewart says, to recognize is that there are different levels of description of the same phenomenon (brain description and subjective experience description)" (pp. 1238-1239).

But this cannot be dualism because the brain is the source and agency of mental events; nor is it a brand of complementarity or process dualism since the brain and its actions are one. Brain events and mental events are neither merely correlated nor simply causally related in some form of interaction; they are one and the same but viewed under different perspectives. My thinking is a brain action, but what I think and why is not analyzable in brain terms. Conversely, mind-brain actions are causally connected to physical behaviors, just as the cognitive processing of the chess player causes how he or she moves the pieces. This applies even to speaking-my mental thought processes are causally related to the movements of my speech apparatus by which I express them. Likewise, this is not monism because the combined mental and physical events are both real and valid, each within its own respective realm, and cannot be translated conceptually one into the other.

\section{Brain-Body Integration}

The brain has a controlling influence on bodily processes, some voluntary and deliberate, some not. We can consider the will as an ego function that exercises an executive capacity by which the self is able to deliberate about, decide on, choose, and execute behavioral sequences. ${ }^{8}$ At times this process or parts of it are conscious, at other times not. The problem of free will (the will as choosing and deciding) is a special case of the agency of the brain exercising a mental function. ${ }^{9}$ The focus falls on the function of will as involving a decision-making process (Meissner, 2003a). How does the brain do this? Damasio and his coworkers (Damasio, 1994; Tranel, Bechara, \& Damasio, 2000) have advanced a possible answer in his "somatic marker hypothesis" linking mental processes with affects in the decision-making 
process. They (Tranel et al., 2000) describe the process as follows:

1. Certain structures in prefrontal cortex are required in order to learn associations between various classes of complex (higherorder) stimuli and various internal states of the organism (such as emotions) ... represented in the brain as transient changes in patterns of activity in somatosensory maps of a large collection of structures, from the brain stem and hypothalamus to the cerebral cortex. We refer to these states as "somatic" (meaning all components of the soma, including the musculoskeletal, the visceral, and the internal milieu).

2. When ... a particular class of complex stimuli recurs in one's ongoing experience, systems in the ventromedial prefrontal region ... trigger reactivation of the somatosensory pattern depicting the appropriate somatic state. This can be achieved by two routes-a body loop or an as-if body loop. In the body loop, the soma actually changes in response to the activation, and signals of those changes are relayed back to somatosensory maps; in the as-if body loop, the reactivation signals are relayed directly to somatosensory maps, bypassing the body and prompting the appropriate pattern of activation in the somatosensory structures. Moreover, each of these mechanisms ... may operate either overtly (consciously) or covertly (unconsciously).

3. With regard to reasoning and decision-making, the reactivation of the somatosensory pattern appropriate in a given situation, concurrent with evocation of pertinent factual knowledge, operates to constrain the reasoning and decision-making space via a qualification mechanism. That is, when the somatosensory pattern image is juxtaposed both to the images prompting the somatic state and those depicting potential outcomes, the somatosensory pattern marks outcomes as good or bad. When it operates covertly, the somatic marker process constitutes a nonconscious biasing signal that facilitates appetitive or avoidance behavior. When it operates overtly, the somatic marker process serves as an incentive or deterrent.

4. Patterns of somatosensory activity can also facilitate attention and working memory, thereby influencing the decisionmaking process indirectly. (p. 1048, emphasis in original)

Obviously, conscious adversion to any of the effects of these processes, whether affective or cognitive-decisional, requires facilitation of attentional and working memory functions. They are also probably required after the somatic-marker processes 
have done their work, in facilitating processes of deliberation, evaluation, inference, and reasoning.

\section{SELF AND BODY}

The next step calls for integration of the brain, as source of action, with the body and both with the concept of self. I have explored the relation of body to self elsewhere in some detail (Meissner, 1997, 1998a, 1998b, 1998c) and will presume those conclusions in this discussion. There is a profound sense in which I am my body. I am my brain. ${ }^{10}$ No two brains are exactly alike. There is enough similarity to allow common neuroanatomical constructions, but there is also a significant degree of individual variation. Even identical twins have a degree of identifiable variation in brain structure, despite the genetic commonalities. If we add the variation introduced from divergent developmental experiences and environmental input, the detailed organization and structure of their respective brains can vary considerably. Every brain is the product of different genetic endowment and different environmental exposure. This accounts for the wide variation not only in brain functioning but in persons and personalities. This presents a common difficulty in the study of brain processes, particularly in higher functions such as language or decision making. There is always a range of variation and individual difference in how individual brains are organized and how they carry out specific functions. In other words, the self is as individual and differentiated as its component parts, and specifically the brain is as differentiated and individualized as the person himself or herself. If we add to this the remarkable plasticity in brain remodeling and repair, the diversity from brain to brain becomes even more impressive.

We can agree in this respect with Modell's (2003) observation that at a minimum modern neuroscience has revealed that some supraneuronal levels of brain functioning may be universal and perhaps impersonal, but also that some are not; some are tied uniquely and idiosyncratically to the patterns of the individual subject's past and present experience. He makes the point that a major task of the brain is the making of meaning, but that making meaning is not reducible to simply processing informa- 
tion. Beyond information processing, meaning involves a selective and value-driven process (à la Edelman) that draws upon bodily need states, personal history, and memory residues of personal experience both cognitive and emotional. This process seems to point toward a more central organizing, selecting, and directing capacity that orchestrates these multiple processes into a coherent pattern sustaining functions of self-regulation and self-awareness.

Thus, conceptualizing the relation of the brain and its actions in these terms leads to further questions of the mind-brain as an integrated system and its relations to the concept of the self. Recent neurobiological and neuropsychological discoveries point to patterns of organization of brain activation that may bear some connection with a central organizing and directing capacity related to self-organization and the regulation of selfrelated functions. The organization of brain processes to produce specific actions is selective and attentional, whether at a deliberative and therefore conscious level, or at a nondeliberative, unconscious level. ${ }^{11}$ Response selectivity, namely, the capacity to inhibit some responses in order to facilitate expression of one or others, reflects the operation of a supervisory attentional system dealing with conflicts of attention or action and with organizing and planning actions, which is probably located in the midline frontal area of the brain (Norman \& Shallice, 2000; Posner \& Rothbart, 1998). In this respect, the anterior cingulate cortex in conjunction with limbic connections seems to play a role in mediating emotional self-regulation (Posner \& Rothbart, 2000), and accordingly may contribute to the operation of the more adaptively functioning cortical supervisory system. ${ }^{12}$ Posner has described this mechanism in terms of an executive control network composed of an anterior portion involving the anterior cingulate cortex and basal ganglia effecting selective attention and executive control within the network, and a posterior portion involving the superior parietal cortex, pulvinar, and superior colliculus providing for attention to and detachment from objects of interest. Associated areas involved in this executive integration include the corpus callosum, amygdala, hippocampal formation, and orbital frontal cortex (Levin, 2002).

Additional information in this regard comes from study of 
the neurobiology of mentalization. Neuroimaging (fMRI) studies reveal a diffuse neural network involving the frontal and temporal cortex and basal ganglia in the development of mentalization (Frith \& Frith, 2003; Giedd, 2003). Mentalizing capacity depends on optimal functioning of the prefrontal cortex (Adolphs, 2003; Rowe, Bullock, Polkey, \& Morris, 2001; Siegel \& Varley, 2002; Stuss et al., 2001), and, in addition, regulation of interpersonal relations, social cooperation, and moral behavior have been connected with functioning of the medial and orbital prefrontal cortices (Damasio, 2003; Greene \& Haidt, 2002; Kelley et al., 2002; Schore, 2003). It also seems that prefrontal cortical controls can similarly be connected with self-awareness (Stuss, 1991; Stuss \& Alexander, 2000; Stuss, Alexander, \& Benson, 1997). These findings open the way to further exploration of the brain processes involved in forms of consciousness, but this important aspect of mind-brain integration and the relation to self-organization, specifically the self-as-subject, would take us far beyond the scope of this present reflection. ${ }^{13}$

Occasionally some piece of neuroscientific discovery seems at times to cast a ray of light into this darkness. A recent study by Fossati et al. (2003) presented words describing positive and negative personality traits to healthy subjects during fMRI scanning. Measures were taken under three conditions: self-referential (subjects thought the trait described them), other-referential (subjects judged whether the stimulus described a generally desirable trait), and a letter-recognition control condition. They report their findings as follows:

The self-referential condition induced bilateral activation in the dorsomedial prefrontal cortex, whereas the other-referential condition induced activation in lateral prefrontal areas. Activation in the right dorsomedial prefrontal cortex was unique to the selfreferential condition regardless of the valence of the words, although positive words produced a more robust activation than did negative words. In the self-referential condition, differences between the processing of positive and negative words were seen in regions outside the medial frontal cortex, with reductions in the insula, temporal and occipital regions, and inferior parietal regions associated with negative words. (p. 1938)

While emotional processing obvious encompasses widely distributed areas of the brain, a significant area mediating self-refer- 
ence seems to be the right dorsomedial prefrontal cortex. I would read these findings as confirmatory of at least some part of the somatic-marker hypothesis.

I understand "body" in this discussion as referring to the physical body and its component parts, the core element of which is the brain, through whose activity bodily processes are synchronized-more or less integrated and orchestrated by virtue of not only complex and mutual feedback processes via direct neuronal connections (peripheral sensorimotor systems) and autonomic nervous system connections, but also by patterns of interaction with endocrine and hormonal systems. But the issue here is not the relation of brain to body, but of body and brain to self. The brain is dynamically and actively involved in constructing a coherent sense of self, whether in the face of or without organic impediments. The mystery is how it accomplishes this task. As Sacks (1995) commented: "That the brain is minutely differentiated is clear: that there are hundreds of tiny areas crucial for every aspect of perception and behavior (from the perception of color and of motion to, perhaps, the intellectual orientation of the individual). The miracle is how they all cooperate, are integrated together, in the creation of a self" (p. xvii).

Dualistic persuasions regarding the organization of the self, largely inspired by Freud's opinions, have been and remain pervasive in psychoanalysis (Meissner, 2003d). Examples include Freud's body ego versus experiencing ego, Federn's (1952) body ego feeling versus psychic ego feeling, Winnicott's $(1958,1971)$ psyche versus soma, Jacobson's (1971) physical self versus mental self, Kohut's (1971) mind-self versus body-self, and Eigen's (1981) "I-feeling associated with body sensation/emotions and the I-feeling connected with thinking-observing" (p. 561)-to mention but a few. Whatever we conclude to be the basic character of the relation, mind depends on body in a way that body does not depend on mind. The mind cannot of itself kill the body, at least not directly, ${ }^{14}$ but the body by way of injury or disease can kill the mind. I would also note that in all such dualistic formulations, the self tends to be conceived by many analytic theorists in bodiless terms, that is, the self is defined in terms of subjective experience and is thereby regarded as dis- 
tinct from and different in kind from the body-a replication of the Cartesian fallacy. Persistence of such dualistic convictions creates a conceptual impasse: How is a bodiless self to be integrated with the body as such?

Analysts have argued the relation of body to self in various terms. Winnicott (1988) had his own version of an identity theory and the origin of the self; as he put it, "The basis of psyche is soma, and in evolution the soma came first. The psyche begins as an imaginative elaboration of physical functioning, having as its most important duty the binding together of past experiences, potentialities, and the present moment awareness, and expectancy for the future. Thus the self comes into existence. The psyche has of course no existence apart from brain and brain functioning" (p. 19). And again, "Human nature is not a matter of mind and body-it is a matter of inter-related psyche and soma, with the mind as a flourish on the edge of psyche-somatic functioning" (p. 26). ${ }^{15}$ It is difficult to tell whether mind and psyche were any more than fantasy constructions, when put in these terms. As Wallace (1988) cogently observed: "To elucidate the physiological underpinnings of humankind's psychologically emergent properties is not to prove the latter nonexistent or to deny their causal efficacy; neither does acknowledging these psychological emergents ... subvert materialism ... because there is more than one way to be material" (p. 8). He goes on to assert, I think correctly, that to acknowledge symbolic or meaning-related capacities does not call for a spirit-matter dualism, nor can a division of psychology (including psychoanalysis) from biology require us to think of the former as exclusively mental or immaterial and the latter as material or physical; indeed, they both study the same basic unit, the organism in interaction with its environment.

From another perspective that I find resonant with my own view, Modell (1993) approached the problem of the self in relation to mind-body by first questioning the theoretical status of the concept of self-representation as a leftover remnant of an atomistic eighteenth-century philosophy, especially of John Locke, suggesting instead that it be conceived as a generative structure. This implies a movement away from the reliance on self-representation as the basis for a psychoanalytic concept of the self, 
a reformulation consistent with my own translation of the selfrepresentation as self-representing, that is, as an action in which the self represents itself to itself as an aspect of the self-as-object (Meissner, 1996), which reflects only one aspect of self-organization. Second, this shift in thinking about the self allows Modell to connect the problem of self-consciousness to Edelman's (1989) model of the self in terms of homeostatic brain systems. He comments: "The continuity of the self is preserved by virtue of the self's linkage with the homeostatic brain systems: the self is the repository of a special value-laden memory system which, persisting over time, interacts with the environment, through reentrant signaling, in real time. Perceptions recurring in real time are recategorized through a 'matching' with these value-laden memories. Thus, the memory structures that generate the sense of self must be continually updated" (p. 163). And further: "A biology of meaning can be derived from Edelman's concept of value. Edelman defines 'value' as evolutionary constraints favoring behavior that fulfills homeostatic requirements or increases fitness. Value is linked to categorical memories relating to appetitive, consummatory, and defensive behavior. Current perceptual events are recategorized in terms of past value-category matches. The self, through this matching and scanning process, assigns value to current experience" (p. 164). Explicating the emergence of consciousness as depicted by Edelman (1992) and Damasio (1999), Miller (2004) comments:

When these autobiographical memories are activated by an individual interacting with objects or contexts that are similar to those which formed the attractor state, their activation influences the perceptual categorization of the here and now. The recategorization of core consciousness in terms of autobiographical memory adds a sense of personal history to the experience of the here and now as well as provides a model upon which to create expectations about the outcomes of actions and about future events. It also creates a sense of self with a past and a future, liberating the experience of self from the here and now constraints of core consciousness. And, with the abilities to symbolically represent declarative (autobiographical, semantic, and episodic) memory, to manipulate these symbols, and to reason about mental contents consciousness is expanded to include imagination, creativ- 
ity, and a higher order sense of self that is often thought of as conscience. (pp. 136-137)

I would qualify Modell's rendition of the self by adding that not only is the self linked to such reiterative and homeostatic memory systems in its objective perspective (i.e., that of the selfas-object; Meissner, 1996), but it also involves functions of agency (self-as-agent; Meissner, 1993) and subjectivity (self-assubject; Meissner 1999a, 1999b) that are active in the processes of remembering and representing by which such memory systems are constituted. ${ }^{16}$ The recategorization of core consciousness in relation to specific memory systems can suffice for effecting changes in the self-as-object but do not speak to the agency and subjectivity of the self.

Starting from the holistic fact of the integrated person or self, we could then distinguish between aspects or properties (Strawson, 1959); for example, we could regard body weight as a physical property, and thinking as mental, but both could be understood as properties of the same whole person. As Strawson argued, in order for any distinctions within the person to make any sense, even dualistic ones, the concept of the person must already have been presupposed. In this sense, we can presume that the basic nature of the self is to be embodied (Meissner, 1998a), that there is nothing that the self does or is that is not body-based, body-related. There is no thinking without the body, that is, the brain; there is no feeling without body. In these terms, I would conclude the exigency of the body as integral to all aspects of the formation and functioning of the self.

In this respect, distinguishing between the self in a hermeneutic or narrative perspective and in the perspective of action, Schrag (1997) commented:

As we shift our focus of attention from the profile of the self in discourse to the profile of the self in action, it is of some urgency that we attend to the status and role of embodiment. This, of course, is not to say that the body was absent in the preceding discussion of the who of discourse. The speaking and narrating subject announces its presence in full bodily attire. It is in the phenomenon of the self in action, however, that the role of the body moves into prominence, enabling a fleshing out of the portrait of the self after postmodernity in its concrete bodily motility 
and significance. It should come as no surprise that a philosophical inquiry into the being and behavior of the human self would need to take up an account of the role of the body in the experience of selfhood. (p. 44)

Schrag further complains that for the most part in discussions of the mind-body relation, the body is cast in terms common to physical bodies in general, defined in terms of extension, mass, figure, and motion. He then argues:

It is precisely the taken-for-granted concept of the human body as simply a thing among other things, an object among other objects, an extension of material substance in general, that needs to be problematized. An inquiry into the meaning of embodiment, as it pertains to the self as the who of discourse and the who of action, requires that one move beyond the traditional metaphysical prejudgments of the human body as an entity defined within the coordinates of extension, mass, and motion, congealed and solidified as an ob-ject, somehow standing over against the mind that putatively perceives it. (p. 47 , emphasis in original)

We are indebted to Merleau-Ponty (1945) for his seminal discussions of the structure and dynamics of the "lived body" as distinct from the body as a merely material object with physiological processes. ${ }^{17}$ This view of embodiment was expressed also by Marcel (1950), who wrote: "My body is my body just in so far as I do not consider it in this detached fashion, do not put a gap between myself and it. To put this point in another way, my body is mine in so far as for me my body is not an object, but rather, I am my body" (p. 123, emphasis in original). Similarly, Heidegger (1979) put the sense of self as embodied as follows:

Ultimately we dare not split up the matter in such a way as though there were a bodily state housed in the basement with feelings dwelling upstairs. Feeling, as feeling oneself to be, is precisely the way we are corporeally. Bodily being does not mean that the soul is burdened by a hulk we call the body. In feeling oneself to be, the body is already contained in advance in that self, in such a way that the body in its bodily states permeates the self. We do not "have" a body in the way we carry a knife in a sheath. Neither is the body a natural body that merely accompanies us and which we can establish, expressly or not, as being also at hand. We do not "have" a body; rather, we "are" bodily. (pp. 98-99) 
It may be that acceptance of the self as embodied connotes that the subject (or object) of psychoanalytic conceptualization is at once mind-in-body and body-in-mind without distinction or differentiation. The pressing problem is how to negotiate that conceptual interphase without the kind of conceptual slippage or assumed equivalence that characterized Freud's thinking about mind-brain (Meissner, 2003c). Unfortunately, as far as I can see, assumptions of equivalence or identity too often slip into some form of neural monism. Is it possible, then, to speak of brain as the organ of mind without undermining or undervaluing the functions of mind as real, valid, and valued? Correspondingly, can we address the uniqueness, reality, and inherent value of the mind and its commerce without being drawn into a dualistic resolution?

The individualization of brain and self go hand-in-hand. As Holland (1988) observed: "Our brains individuate more during our development than do hearts, pancreases, or our other organs. The brain grows in childhood, and it un-grows as we approach adolescence. In the process, each of our brains becomes a somewhat different brain, and out of that individual brain comes a personal style-an identity. The brain is the organ of the unique mind by which we read and rote in individual ways" (p. 154). We should keep in mind that, while neurophysiological activity is a necessary condition for operations of mind, such that there are no mental operations that do not originate in neurological processes, at the same time the brain is not of itself both a necessary and sufficient condition for explaining operations of the mind: multiple organ systems have to interact, as well as continuing interaction with the external environment, in order to maintain mental activity (Wallace, 1988, 1990). On these terms the integrated sense of body and self, which is objectively given and real, is maintained subjectively by the continuous flow of proprioceptive input from all parts of the body, on both conscious and unconscious levels-in Sherrington's (1906) terms, it is by proprioceptive information that we feel that our bodies belong to us, as not only our property, but as part of ourselves. ${ }^{18}$

I would further suggest when such proprioceptive functions are interrupted or disturbed, the underlying integrity of the mind-body can reassert itself in other sensorially mediated 
terms. In patients who have lost the proprioceptive sense there is a feeling of disconnection from the body-as in states of psychic disconnection also mediated by a dissociated body image. But the loss, even when neurologically caused, is gradually compensated by amplification of other senses. As Sacks (1970) noted of one such patient:

Increasingly now, week by week, the normal, unconscious feedback of proprioception was being replaced by an equally unconscious feedback by vision, by visual automatisms and reflexes increasingly integrated and fluent. Was it possible, too, that something more fundamental was happening? That the brain's visual model of the body, or body-image . . normally subsidiary to the proprioceptive body-model ... was gaining, by way of compensation or substitution, an enhanced, exceptional, extraordinary force? And to this might be added a compensatory enhancement of the vestibular body-model or body-image. (pp. 48-49)

Such compensations do not replace a lingering sense of disembodiment, but even in the loss of a function so intimately connected and vital to the sense of bodily unity an effective degree of functional feeling of bodily integration can be regained by enhancement of other functions.

We can also add that clinical evidence suggests that injury or impairment of brain functions results not only in loss of bodily function but in effects on the personality organization of the affected individual (Sacks, 1970). A great deal has been learned in this respect about mind-brain relations and the organization of the self. Victims of stroke or trauma can suffer severe disruptions of their normal functioning and seem in certain ways different from the way they were before injury. ${ }^{19}$ They are not quite the same person as before-as if to change the brain is to change the person. As Sacks (1970) observed: "The patient's essential being is very relevant in the higher reaches of neurology, and in psychology; for here the patient's personhood is essentially involved, and the study of disease and of identity cannot be disjoined. Such disorders, and their depiction and study, indeed entail a new discipline, which we may call the "neurology of identity,' for it deals with the neural foundations of the self, the age-old problem of mind and brain" (p. viii). ${ }^{20}$

Referring to confabulation in the Korsakoff amnesic syn- 
drome, Sacks (1970) pointed out that the patient is "continually creating a world and self, to replace what was continually being forgotten and lost ... for such a patient must literally make himself (and his world) up every moment" (p. 110, emphasis in original). The paradox, of course, is that we all do something similar in every waking moment; the difference is that we are aided in the process by the resources of memory and the continuity of consciousness and self-consciousness. This, I think, can have particular relevance for how we conceptualize the therapeutic action of psychoanalysis-that the recovery, exploring, understanding, and reformulating of such memories provides the basis for psychic structural change and reshaping of the sense of self and identity. As Sacks (1970) put it: "To be ourselves we must have ourselvespossess, if need be re-possess, our life stories. We must 'recollect' ourselves, recollect the inner drama, the narrative, of ourselves. A man needs such a narrative, a continuous inner narrative, to maintain his identity, his self" (p. 111, italics in original). In some fundamental sense, then, my personal identity is embedded in my memory, especially but not exclusively my episodic and autobiographical memory. As Andreasen (2001) writes:

We are our memories. The personal identity, the sense of self that each of us has, is the composite of the episodic memories that we have retained and draw on each time we think a thought, experience a feeling, or make a decision. Episodic memory, a sequentially time-linked memory system, permits us to have a sense of the future as well as the past and present. Because we can place ourselves within the linear context of time, we can look forward as well as back.... Our capacity to think within the context of time is the backbone of our psyche. (p. 60)

Obviously episodic memory does not tell the whole story. Undoubtedly the sense of self and personal identity involves attentional mechanisms, aspects of working memory, linguistic referential components, self-referential consciousness, the persistence through time and space of the physical body, even the external stability of the surrounding environment and the internal physical structural components of the self. If I remember, there must be not only memories, but an "I" who remembers. In relation to cognitive functions, neuroscientists speak of a "central executive" or "supervisory attentional system" that man- 
ages attention, selection, and control of functions involved in working memory (Baddely, 1986, 2000; Goldman-Racik, 2000) and that is compounded of a variety of special purpose domains centered in the prefrontal granular cortex. ${ }^{21}$ Each of these domains encompasses local and extrinsic networks involving sensory, mnemonic, motor, and motivational components. The central executive cannot be the neurological equivalent of the self, but these related processes may have a lot to do with self-related activity and organization. In these considerations, we should also be careful to distinguish in this context the self-as-agent, synonymous and coextensive with the body self (Meissner, 1997) from the self-as-subject (Meissner, 1999a, 1999b) and self-as-object (Meissner, 1996). Even if the latter subjective and experiential components of the self are completely dormant-as they may be, for example, in cases of deep coma-the self-as-agent remains present and active. The identity of the person in such cases is preserved bodily and in terms of body actions but not subjectively. ${ }^{22}$

Indeed, even non-neurological changes in the body exert direct effects on the self-concept, mediated through changes in self-representation, usually through the impact of alterations in the body image, as referencing the self-as-object. Formation of the body image, therefore, plays a critical role in the forming of self-representations as an integral component of the self-asperson (Lemche, 1998; Meissner, 1996, 1997, 1998b). Surgical amputation, for example, can have the effect of a narcissistic assault reinforcing the sense of oneself as defective, shamefully inadequate, distorted, and ugly. In all such cases, clinicians have discerned a built-in dynamic, a striving, to maintain or reconstitute a sense of integral personhood and identity in the face of neurological or other bodily insults. Further, as Andrade (2005) points out, if introjection or identification with the analyst in the course of analysis can modify the patient's self, modern neuroscientific discoveries tell us that corresponding modifications of neural circuits are taking place in the brain. He concludes: "When we talk of introjection and psychic change we are simply describing in metapsychological terms what is taking place neurochemically. It is appropriate to reason in this way if you believe in a brain-mind continuum, where the existence of psychic phe- 
nomena which are not an expression of some activity in the brain is inconceivable" (p. 685, emphasis in original).

\section{SUMMARY AND THEORETICAL CONCLUSIONS}

The preceding reflections lead me to draw the following conclusions regarding integration of the mind-body relation with a theory of the self:

1. Given the problems with either commonly held dualistic or monistic solutions regarding the mind-body relation, some other resolution is required for a comprehensive psychoanalytic understanding of the meaning of the self (Meissner, 2003b). Freud's ambiguity in dealing with this problem, marked by considerable vacillation and ultimately leaning more in the direction of parallelism than identity theory (Meissner, 2003c), left an uncertain legacy to subsequent generations of psychoanalytic theorists, among whom almost every monistic and dualistic solution finds acceptance. Opinions for the most part hover around a dualistic center with minor variations on the theme. While many acknowledge some form of as-yet unknown ultimate integration of mind and brain, there is reluctance to treat them in a unifying frame of reference out of reductionistic concerns that would grant priority to the physical to the detriment and devaluation of the mental.

2. Recent advances in neurobiological techniques have created a revolution in the study of the brain. Neuroimaging and recording techniques have extended study of brain action to detailed processes in individual cells and in cell networks and complex circuits that reveal the parts of the living brain activated in the performance of not only external behaviors but of psychological mental processes as well. Not only is the activity of the brain revealed in all such processes but the details of brain activation can now be much more closely linked with and related to psychological activity. As many have argued, this introduces a new and different dimension to the understanding of brain action: We can see the relevant parts of the brain go into action as the brain performs an activity, whether physical or mental. As in all other cases in which we are able to see an agent acting, I would conclude that all forms of behavior result from actions of 
the brain and all forms of mental activity are synonymously actions of the brain. This goes beyond mere correspondence to some form of identity - but what kind? (Meissner, 2006a, 2006b, 2008b).

3. Brain activity is one thing, the products of brain activity are another. Whatever relevance of dualistic resolutions of the mind-brain problem might have rested on this perception, the problem is how to conceive their relation. Reduction of one to the other is neither necessary nor helpful. If I argue that one is the cause of the other, is there any question of reduction? The meaning and content of my thought is quite different and independent of what happens in my brain, but without the brain action there would be no thought. I see no reason for not viewing this as a causal process from beginning to end, the various phases of which call for different techniques of study and methods of exploration. I can say that the mental processes of thinking about the content of this essay are in some basic sense actions of my brain, and make perfectly good sense. But this understanding implies that there is no question of my statement meaning that any of the meaning and logic of the essay can in any way be explored or conceptualized by neurophysiological analysis.

4. The theoretical conclusion regarding the concept of the self is that the self, as embodied, is corporeal in all aspects of its organization and function. The brain operates as the core constituent of self-organization and is capable of producing and directing both physical and mental actions. All mental actions, including self-consciousness and the sense of personal identity, are aspects of brain activity (Meissner, 2008b).

5. Although they are connected as agent-and-action, the effected actions are subject to analysis and understanding on their own terms regardless of neurophysiological dependence or causality. Physical actions require analysis in physical terms and mental actions require analysis in mentally correlative terms. Thus, psychoanalysis studies primarily mental actions, conscious and unconscious-ideas, thoughts, verbalized mentation, wishes, fantasies, dreams, and so forth-and analyses them by analytic concepts and methods that have significance independently from the neurophysiological processes behind them even 
though they are fundamentally both investigating a single source and process. All of which seems, to my thinking, to point the potential for psychoanalytic progress in the direction of expanding or deepening the concept of the mind-body relation in which mental and bodily events are conceived not as exclusive, but as products of the same integrated and unified underlying source.

\section{NOTES}

1. Dualism is a view of the mind-body relation that postulates mind and body as separate entities, operating in conjunction and/or correlation in the performance of specific functions. Mental activity in this view cannot be reduced to or caused directly by the action of the brain, but they are related in some manner. The problem for dualism is how to explain this connection. In contrast, strictly monistic theories hold that the mental and the physical are one and the same, assuming either that the reality in question is entirely mental (idealistic) or physical (materialistic). The mind-body problem in reductive terms is resolved by eliminating one or other side of the equation. The problem for reductionism is that it reduces one or other aspect of the equation to meaningless terms. For example, if mental life is reduced to nothing more than brain action, that is, if it is the same as brain action, man's mental life is nothing more than an epiphenomenon without any meaningful reality. My conclusion (Meissner, 2003b) is that these viewpoints and their related alternatives should be rejected. The reductionistic approach is less of a problem for psychoanalysts since the meaningfulness of an interior and subjective psychic life dominates our concerns. However, dualism in its various forms and varieties is common, if not pervasive, among analytic theorists. In recent years, largely responding to the progressive interest in and influence from neuroscientific discoveries, the analytic ground is shifting toward the perspective I am reporting on in the present reflection. But progress is slow-the prevailing orientation, judging from reading of the current analytic literature, is still largely dualistic (Meissner, 2003d).

2. I would like to draw attention to Schmidt-Hellerau's (2001, 2002) ambitious attempt to construct a neurologically based model, utilizing in large measure the contributions of Luria, that would correspond to dimensions of the analytic structural tripartite theory. The result is noteworthy in that it demonstrates that any and all functions attributable to id, ego, and superego can be mediated by neurological systems. This underlines once more, to my reading, the conclusion that the brain is in effect the organ of mind.

3. Schore (2002) commented that when self psychology, along with analysis in general, seeks to dispense with the body, overemphasizing cognitive and verbal aspects, it falls into the Cartesian error, or, as Damasio (1994) put it, "the separation of the most refined operations of mind from the structure and operation of a biological organism" (p. 250).

4. The same perspective is extended in Damasio's (1999) more recent account 
of the origins of affect and consciousness, namely, that brain, consciousness, and affect are interactive and integrated within as well as inseparable from the brain and body.

5. Leuzinger-Bohleber and Pfeifer (2002) pointed to the issue of frames of reference, that is, that observable behaviors and brain mechanisms occupy separate frames of reference and therefore cannot be reduced one to the other. Such a reduction may constitute a category mistake if one were to do so, but a view of brain mechanisms and behaviors related as cause and effect or as agent and action would not seem to me to run that risk.

6. This attitude toward the subjective self, in terms of its relation to the first personal "I," is typical of much of contemporary postmodern thought, not merely among those who espouse an epiphenomenal view of the self. See the discussion in Globus (1980).

7. Some critics have been troubled by the notion of causality in this context. The objection takes the following form: If mental actions are caused by the brain, causality implies separateness-the separateness of cause and effect. If cause (brain) and effect (mind) are separate, the result is that brain and mind are separate. This is dualism. Or, in other terms, the statement that "A is a form of $\mathrm{B}$ " is irreconcilable with the statement " $\mathrm{A}$ is the cause of B." A cannot be both form of and cause of B. In the present perspective, this dramatizes the problem in stating what the relation is between the thought of the triangle and the brain action producing it. Cause and effect are distinct-the brain action is not the thought, and the thought is not the brain action. But the causal connection between them integrates them in a unique manner. The thought cannot have separate existence without the brain action. It is both expressed in and produced by the brain action. The linguistic difficulty is apparent. But, in the final analysis, it may not distort the reality to say that the thought is both a form of brain action and the result of brain action without contradiction. To take another example, thinking about and deciding to move the chess piece, then actually moving it, is a causal sequence in which physically moving the piece is the result of the thinking process. The actions are distinct, but the movements of my arm and hand are my actions just as much as the related thinking is my action. If the quality of the actions can be distinguished (mental vs. physical) they are both actions of the same agency, both forms of action of that agency (however otherwise distinguishable), and both caused by that same agency.

8. I have explored the nature and function of the will in psychoanalytic terms in Meissner (2008b).

9. The eminent psychologist George Miller used to challenge his students to come up with any psychological principle that could not be violated by an act of will. Not finding any, he opined, "Now, however, I would simply change my value judgment. The ability to violate some principle by an act of will is now the critical test that the principle in question is one that is relevant to psychology" (cited in Gazzaniga, 2000, p. 7).

10. After completing this discussion, LeDoux's (2002) recent book fell into my hands. As far as I can see, he is driving at a similar conclusion regarding the integration of mind, brain, and self using a bottom-up approach in contrast to my top-down argument. He comments: "My notion of personality is pretty simple: it's that your 'self,' the essence of who you are, reflects 
patterns of interconnectivity between neurons in your brain. Connections between neurons, known as synapses, are the main channels of information flow and storage in the brain. Most of what the brain does is accomplished by synaptic transmission between neurons, and by calling upon the information encoded by past transmission across synapses" (p. 2). Furthermore, "When I use the term the self I am referring to the totality of the living organism" (p. 26, emphasis in original). As far as I can see this view is up to a point congruent with my concept of the self-as-person (Meissner, 2001) as synonymous with the body self (Meissner, 1997). The same perspective is reinforced by Damasio (1999): "A mind is so closely shaped by the body and destined to serve it that only one mind could possibly arise in it. No body, never mind. For any body, never more than one mind" (p. 143). However, LeDoux (2002) may go beyond my concept of the self when he says, "In my view, the self is the totality of what an organism is physically, biologically, psychologically, socially, and culturally" (p. 31). I can agree with the physically, biologically, and psychologically, but social and cultural influences, while they shape the sense of self, particularly as reflected in the self-as-object (Meissner, 1996), remain extrinsic to the self as such. See my discussion of the self-as-social (Meissner, 2003e, 2009a, 2009b).

11. The role of nondeliberative thinking below the level of conscious awareness has been suggested by Rangell (1986) and further developed in Meissner (2003a, 2008b). Such thinking may be involved in decisional processes, secondary process in nature, below the level of conscious awareness.

12. See the further discussion of self-regulation and executive functions in Baumeister and Vohs (2003).

13. I have addressed these issues further in Meissner (2008a).

14. Even in suicide, the mind can decide to kill the body, but cannot do so without enlisting help from the body.

15. To the same point: "The psyche part of the person is concerned with relationships, relationships within, relationships to the body, to the external world. Arising out of what may be called the imaginative elaboration of body functioning of all kinds and the accumulation of memories, the psyche (specifically dependent on brain functioning) binds the experienced past, the present and the expected future together, makes sense of the person's sense of self, and justifies our perception of an individual there in that body" (Winnicott, 1988, p. 28).

16. A more extensive discussion of the relevance of Edelman's model for exploring the basis of consciousness and related functions in attempting to articulate psychoanalytic psychic functions and their integration with brain actions can be found in Davis (2002).

17. Along the same line, Scheler (1973) distinguished between "lived-body" (Leib) and "thing-body" (Körper).

18. I take this to be the substantive point of Damasio's (1994) somatic-marker hypothesis.

19. The important historical case first exemplifying radical change in personality after brain injury was that of Pineas Gage. The Gage story is retold in Damasio (1994).

20. The same theme is reiterated in Sacks (1995).

21. Recent findings and theories regarding working memory, attention, and central prefrontal executive functions and their relation to consciousness 
are discussed in LeDoux (2002). See also the preceding discussion of central executive functions.

22. As Damasio (1994) noted, the neurological basis for the self extends beyond the requirements for the wakefulness and awareness of subjectivity, of the self as knowing and experiencing. The neural basis undergirding the processes we associate, for example, with the subjective self are at a different level and of a different order than processes affecting the full scope of self-consciousness. Thus, self-as-object and self-as-subject are both aspects of the same self-system but result from different functional integrations of the neural net.

\section{REFERENCES}

Adolphs, R. (2003). Cognitive neuroscience of human social behavior. Nature Reviews, 4:165-178.

Andrade, V. M. (2005). Affect and the therapeutic action of psychoanalysis. Internat. J. Psycho-Anal., 86:677-697.

Andreasen, N. C. (2001). Brave new brain: Conquering mental illness in the era of the genome. New York: Oxford University. Press.

BADDEley, A. (1986). Working memory. London: Oxford University Press.

(2000). Working memory: The interface between memory and cognition. In M. S. Gazzaniga, ed., Cognitive neuroscience: A reader (pp. 292-304). Oxford: Blackwell.

Baumeister, R. F., \& Vohs, K. D. (2003). Self-regulation and the executive function of the self. In M. R. Leary \& J. P. Tangney, eds,. Handbook of self and identity (pp. 197-217). New York: Guilford Press.

Crick, F. (1994). The astonishing hypothesis: The scientific search for the soul. New York: Simon \& Schuster.

Damasio, A. R. (1994). Descartes' error: Emotion, reason, and the human brain. New York: G. P. Putnam's Sons.

(1999). The feeling of what happens: Body and emotion in the making of consciousness. San Diego: Harcourt.

(2003). Looking for Spinoza: Joy, sorrow, and the feeling brain. New York: Harvest Books.

Davis, S. M. (2002). The relevance of Gerald Edelman's theory of neuronal group selection and nonlinear dynamic systems for psychoanalysis. Psychoanal. Inq., 22:814-840.

Edelman, G. (1989). The remembered present: A biological theory of consciousness. New York: Basic Books.

(1992). Bright air, brilliant fire. New York: Basic Books.

EIGEN, M. (1981). Maternal abandonment threats, mind-body relations and suicidal wishes. J. Amer. Acad. Psychoanal., 9:561-582.

Erwin, E. (2002). Mind and body. In E. Erwin, ed., The Freud encyclopedia: Theory, therapy and culture (pp. 343-345). New York: Routledge.

Federn, P. (1952). Ego psychology and the psychoses. New York: Basic Books.

Fossati, P., Hevenor, S. J., Graham, S. J., Grady, C., Keightley, M. L., Craik, F., \& Mayberg, H. (2003). In search of the emotional self: An fMRI study using positive and negative emotional words. Amer. J. Psychiatry, 160: $1938-1945$. 
Frith, U., \& Frith, C. D. (2003). Development and neurophysiology of mentalizing. Philosoph. Transactions of the Royal Society of London, 358:459-473.

Gazzaniga, M. S. (2000). Life with George: The birth of the Cognitive Neuroscience Institute. In M. S. Gazzaniga, ed., Cognitive neuroscience: A reader (pp. 4-13). Oxford: Blackwell.

GiedD, J. (2003). The anatomy of mentalization: A view from developmental neuroimaging. Bull. Menn. Clin., 67:132-142.

Globus, G. G. (1980). On "I": The conceptual foundations of responsibility. Amer. J. Psychiatry, 137:417-422.

Goldman-Racik, P. S. (2000). Architecture of the prefrontal cortex and the central executive. In M. S. Gazzaniga, ed., Cognitive neuroscience: A reader (pp. 391-402). Oxford: Blackwell.

Goleman, D. (1995). Emotional intelligence. New York: Bantam Books.

Greene, J., \& Haidt, J. (2002). How (and where) does moral judgment work? Trends in Cognitive Neurosci., 6:517-523.

Heidegger, M. (1979). Nietzsche: Vol 1. The will to power as art (D. F. Krell, trans.). San Francisco: Harper San Francisco, 1991.

Holland, N. N. (1988). The brain of Robert Frost: A cognitive approach to literature. New York: Routledge.

Jacobson, E. (1971). Depression. New York: International Universities Press.

Kelley, W. M., Macrae, C. N., Wyland, C. L., Caglar, S., Inati, S., \& HeatherTON, T. F. (2002). Finding the self? An event-related MRI study. J. Cognitive Neurosci., 14:785-794.

KoHut, H. (1971). The analysis of the self. New York: International Universities Press.

LeDoux, J. (2002). Synaptic self: How our brains become who we are. New York: Viking Penguin.

Lemche, E. (1998). The development of the body image in the first three years of life. Psychoanal. Contemp. Thought, 21:155-275.

Leuzinger-Bohleber, M., \& Pfeifer, R. (2002). Remembering a depressive primary object: Memory in the dialogue between psychoanalysis and cognitive science. Internat. J. Psycho-Anal., 83:3-33.

LeVIn, F. M. (2002). Attention deficit disorder: A neuropsychoanalytic sketch. Psychoanal. Inq., 22:336-354.

Marcel, G. (1950). The mystery of being: Vol. 1: Reflection and mystery. Chicago: Henry Regnery, Gateway Edition.

Meissner, S. J., W. W. (1993). The self-as-agent in psychoanalysis. Psychoanal. Contemp. Thought, 16:459-495.

(1996). The self-as-object in psychoanalysis. Psychoanal. Contemp. Thought, 19:425-459.

(1997). The self and the body: I. The body self and the body image. Psychoanal. Contemp. Thought, 20:419-448.

(1998a). The self and the body: II. The embodied self-self vs. nonself. Psychoanal. Contemp. Thought, 21:85-111.

(1998b). The self and the body: III. The body image in clinical perspective. Psychoanal. Contemp. Thought, 21:113-146.

(1998c). The self and the body: IV. The body on the couch. Psychoanal. Contemp. Thought, 21:277-300.

(1999a). The self-as-subject in psychoanalysis: I. The nature of subjectivity. Psychoanal. Contemp. Thought, 22:155-201. 
(1999b). The self-as-subject in psychoanalysis: II. The subject in analysis. Psychoanal. Contemp. Thought, 22:383-428.

(2000a). The self as structural. Psychoanal. Contemp. Thought, 23:373416.

(2000b). The structural principle in psychoanalysis: I. The meaning of structure. Psychoanal. Contemp. Thought, 23:283-330.

(2000c). The structural principle in psychoanalysis: II. Structure formation and structural change. Psychoanal. Contemp. Thought, 23:331-371.

(2001). The self-as-person in psychoanalysis. Psychoanal. Contemp. Thought, 23:479-523.

(2003a). The ethical dimension of psychoanalysis-A dialogue. Albany, NY: State University of New York Press.

(2003b). Mind, brain, and self in psychoanalysis: I. Problems and attempted solutions. Psychoanal. Contemp. Thought, 26:279-320. $(2003 c)$. Mind, brain, and self in psychoanalysis: II. Freud and the mind-body relation. Psychoanal. Contemp. Thought, 26:321-344. (2003d). Mind, brain, and self in psychoanalysis: III. Psychoanalytic perspectives after Freud. Psychoanal. Contemp. Thought, 26:345-386. (2003e). The self-as-social. Psychoanal. Contemp. Thought, 26:147-194. (2006a). The mind-brain relation and neuroscientific foundations: I. The problem and neuroscientific approaches. Bull. Menn. Clin., 70:87101.

(2006b). The mind-brain relation and neuroscientific foundations: II. Neurobehavioral integrations. Bull. Menn. Clin., 70:1102-124.

(2006c). The mind-brain relation and neuroscientific foundations: III. Brain and psychopathology, the split-brain, and dreaming. Bull. Menn. Clin., 70:179-201.

(2006d). Psychoanalysis and the mind-body relation: Psychosomatic perspectives. Bull. Menn. Clin., 70:295-315.

(2008b). Volition and will in psychoanalysis. Unpublished manuscript. (2009a). The genesis of the self: I. The self and its parts. Psychoanal. Rev., 96:189-219.

(2009b). The genesis of the self: IV. Implications for the analytic relation and process, Part II: The self as interactive. Psychoanal. Rev., 96:337368.

(in press). Mind-brain and consciousness in psychoanalysis. Bull. Menn. Clin., 72:283-312.

Merleau-Ponty, M. (1945). Phenomenology of perception. London: Routledge and Kegan Paul, 1962.

Miller, M. L. (2004). Dynamic systems and the therapeutic action of the analyst. In J. Reppen, J. Tucker, \& M. A. Schulman, eds., Way beyond Freud: Postmodern psychoanalysis observed (pp. 132-155). London: Open Gate Press.

Modell, A. H. (1993). The private self. Cambridge, MA: Harvard University Press.

(2003). Imagination and the meaningful brain. Cambridge, MA: MIT Press.

Norman, D. A., \& Shallice, T. (2000). Attention to action: Willed and automatic control of behavior. In M. S. Gazzaniga, ed., Cognitive neuroscience: A reader (pp. 377-390). Oxford: Blackwell. 
Posner, M. I., \& Rothbart, M. K. (1998). Attention, self-regulation and consciousness. Philosoph. Transactions of the Royal Society, 353:1915-1927.

$\&$ _ (2000). Developing mechanisms of self-regulation. Dev. Psychopathology, 12:427-441.

Rangell, L. (1986). The executive functions of the ego: An extension of the concept of ego autonomy. Psychoanal. Study of the Child, 41:1-37.

Rorty, A. O. (1988). Mind in action: Essays in the philosophy of mind. Boston: Beacon Press.

Rorty, R. (1979). Philosophy and the mirror of nature. Princeton, NJ: Princeton University Press.

Rowe, A. D., Bullock, P. R., Polkey, C. E., \& Morris, R. G. (2001). “Theory of mind" impairments and their relation to executive functioning following frontal lobe excisions. Brain, 124:600-616.

Ryle, G. (1949). The concept of mind. New York: Barnes \& Noble, 1967.

SACKs, O. (1970). The man who mistook his wife for a hat and other clinical tales. New York: Simon \& Schuster. (1995). An anthropologist on Mars: Seven paradoxical tales. New York: Vintage Books.

SCHELER, M. (1973). Formalism in ethics and non-formal ethics of values. Evanston, IL: Northwestern University Press.

Schmidt-Hellerau, C. (2001). Life drive and death drive-Libido and lethe: A formalized consistent model of psychoanalytic drive and structure theory. New York: Other Press.

(2002). Where models intersect: A metapsychological approach. Psychoanal. Quart., 71:503-544.

Schore, A. N. (2002). Advances in neuropsychoanalysis, attachment theory, and trauma research: Implications for self psychology. Psychoanal. Inq., 22: $433-484$.

(2003). Affect regulation and the repair of the self. New York: Norton.

Schrag, C. O. (1997). The self after postmodernity. New Haven, CT: Yale University Press.

Sherrington, C. (1906). The integrative action of the nervous system. New Haven, CT: Yale University Press, 1961.

Siegel, M., \& VARley, R. (2002). Neural systems involved in "theory of mind." Nat. Rev. Neurosci., 3:463-471.

STEwart, H. (1997). The ontology of mind: Events, processes and states. Oxford: Oxford University Press.

Stoller, R. J. (1979). Sexual excitement: Dynamics of erotic life. New York: Pantheon.

Strawson, P. (1959). Individuals. London: Menthuen.

Stuss, D. T. (1991). Self, awareness, and the frontal lobes: A neuropsychological perspective. In J. Strauss \& G. R. Goethals, eds., The self: Interdisciplinary approaches (pp. 255-278). New York: Springer Verlag.

\& Alexander, M. P. (2000). Executive functions and the frontal lobes: A conceptual view. Psychol. Res./Psychologische Forschung, 63:289-298.

, \& Benson, D. F. (1997). Frontal lobe functions. In M. R. Trim-

ble \& J. L. Cummings, eds., Contemporary behavioral neurology: Blue books of practical neurology (Vol. 16, pp. 169-187). Woburn, MA: ButterworthHeinemann. 
Gallup, G. G., JR., \& Alexander, M. P. (2001). The frontal lobes are necessary for "theory of mind." Brain, 124:279-286.

Tranel, D., Bechara, A., \& Damasio, A. R. (2000). Decision making and the somatic marker hypothesis. In M. S. Gazzaniga, ed., The new cognitive neurosciences (pp. 1047-1061). Cambridge, MA: MIT Press.

Wallace, E. R. (1988). Mind-body: Monistic dual aspect interactionism. J. Nerv. Mental Dis., 176:4-21.

(1990). "Mind"/"body" and the future of psychiatry. J. Med. Philosophy, 15:41-73.

Wilson, M. (2005). Review of A. Goldberg, Misunderstanding Freud. Internat. J. Psycho-Anal., 86:1237-1241.

Winnicott, D. W. (1958). Collected papers: Through pediatrics to psychoanalysis. London: Hogarth Press.

(1971). Playing and reality. New York: Basic Books. (1988). Human nature. New York: Schocken Books.

St. Mary's Hall

Boston College

140 Commonwealth Avenue

Chestnut Hill, MA 02467

E-mail: Meissner@bc.edu
The Psychoanalytic Review Vol. 96, No. 2, April 2009 